\title{
-Original-
}

\section{Epidemiological and Clinical Aspects of Human Brucellosis in Eastern Anatolia}

\author{
Cenk Aypak $^{1}$, Adalet Altunsoy ${ }^{2}$ and Ali Kutta Çelik ${ }^{2}$ \\ ${ }^{1}$ Department of Family Medicine, Gevas Hospital, Turkey \\ ${ }^{2}$ Department of Clinical Microbiology and Infectious Diseases, Van Education and Research Hospital, Turkey
}

\begin{abstract}
Background: We investigated the seroprevalence of human brucellosis and risk factors in a village in Eastern Anatolia, Turkey, where a brucellosis outbreak among cattle had recently occurred.

Patients and Methods: All 501 inhabitants enrolled were screened with the Rose Bengal Test and were asked to fill out a questionnaire to determine the signs and symptoms of brucellosis and the risk factors. Patients' laboratory findings and clinical responses were also evaluated.

Results: The Rose Bengal Test was positive in 44 persons. In comparison of age groups, fever $(20.2 \%)$, arthralgia (19.2\%) and weight loss $(8.4 \%)$ were frequently seen in children $(p<$ 0.05). Hepatomegaly (17.9\%) was also prevalent in the age group of 0 to 14 years $(p<0.05)$. The consumption of dairy products, a family history of brucellosis, and raising livestock were significantly related to seropositivity $(p<0.05)$. Rifampicin plus doxycyline was the most common regimen administered in these cases $(54.5 \%)$ and also had the highest relapse rate $(p<$ 0.05).
\end{abstract}

Conclusion: Brucellosis remains an important public-health problem in the rural areas of Turkey. Appropriate public health measures and education must be pursued to eradicate human brucellosis.

(J Nippon Med Sch 2012; 79: 343-348)

Key words: brucellosis, epidemiology, signs, symptoms, treatment outcome

\section{Introduction}

Brucellosis is primarily a zoonosis caused by Gram-negative bacteria Brucella spp. and is transmissible to humans through direct contact with infected animals, consumption of dairy products, or inhalation of aerosols ${ }^{1}$. Brucellosis has been controlled through aggressive public health measures in developed countries but remains a concern in many parts of the world, especially in Asia and the Mediterranean region ${ }^{2}$. The true prevalence and incidence are unknown owing to misdiagnosis and underreporting.

Brucellosis is a multisystemic disease that shows wide clinical polymorphism. Its main clinical

Correspondence to Cenk Aypak, Department of Family Medicine, Gevas Hospital, 65110, Van, Turkey

E-mail: cenkaypak@yahoo.com

Journal Website (http://www.nms.ac.jp/jnms/) 


\section{Aypak, et al}

manifestations are fever, headache, anorexia, fatigue, arthritis, hepatosplenomegaly, and neurological signs. It may progress as a subclinical, acute, subacute, or chronic infection'. Brucellosis can have serious consequences for public health because of the long treatment, slow recovery, and possible serious sequelae in the motor and nervous systems ${ }^{1}$. Brucellosis it is often misdiagnosed because it can mimic various multisystem diseases and causes complications.

Brucellosis can cause an abortion storm in livestock herds ${ }^{3}$. Such an occurrence was reported to the local veterinary officials by cattle breeders in the village of Aydinocak, located $80 \mathrm{~km}$ southwest of Van province one of the largest cities with one million inhabitants in eastern Turkey in January 2010.

Because of the public health implications of brucellosis, the purpose of this study was to investigate the seroprevalence of and risk factors for human brucellosis in a rural area of Eastern Anatolia, where a brucellosis outbreak among cattle had recently occurred, and to clarify the manner of infection by evaluating the clinical signs and the outcome of antibiotic therapy.

\section{Materials and Methods}

The population of Aydinocak village was 501 according to government records. In January 2010, all 501 inhabitants were examined by local physicians and were included in the study. A structured questionnaire inquiring into demographic, health, and risk factor data was collected. Screening was done with Rose Bengal Plate Test (RBPT). All positive RBPT results were confirmed with the serum tube agglutination test (STAT) in the second phase. Titers were considered significant if they were determined to be $1 / 160$ and greater with the STAT. Serologic tests were performed according to previously described techniques.

Brucellosis was diagnosed on the basis of a compatible clinical picture, supported by the detection of specific antibodies or the demonstration of an at least 4-fold rise in antibody titer in serum specimens obtained over 4 weeks or both. An adequate response to antibrucellosis therapy was also accepted for diagnosis in persons in whom the STAT was negative.

Cases of were brucellosis divided into 3 groups according to history, symptoms, and clinical presentation time: acute (0-2 months), subacute (2-12 months), and chronic (>12 months). All patients underwent routine laboratory tests. Patients' history, clinical findings, and clinical outcomes were also investigated. After the treatment period, all patients were recalled for the first control visit and then at 4 and 12 weeks and 6 months later. At control visits, complete blood count, C-reactive protein (CRP), erythrocyte sedimentation rate (ESR), and liver enzymes were investigated and the STAT was performed.

\section{Statistical Analysis}

All statistical analyses were performed with using SPSS software package (SPSS for Windows, Version 13.0, SPSS Inc., Chicago, IL, USA). Categorical variables were compared by means of the chi-square test of independence or with Fisher's exact test when conditions for the chi-square test were not met. Univariate analysis was performed by computing the matched odds ratios and their 95\% confidence intervals for the study of risk factors associated with the seropositivity of Brucella spp. A $P$-value less than 0.05 was considered to indicate statistically significant. All tests were two-sided.

\section{Results}

Of the 501 inhabitants, 272 (54.3\%) were female and 229 (45.7\%) were male. The mean age was 24.6 \pm 18.7 years; $189(37.7 \%)$ inhabitants were aged 0 to 14 years, 155 (31\%) were aged 15 to 29 years, 60 (12\%) were aged 30 to 44 years, 90 (18\%) were aged 45 to 59 years, and 7 (1.3\%) were 60 years or older.

The RBPT was positive in $44(8.8 \%)$ persons. These persons ranged in age from 2 to 79 years and had a mean age of $25 \pm 18.6$ years. Twenty-three $(52.3 \%)$ of these persons were female. None of the RBT-positive women were pregnant. The frequency of various symptoms and physical findings of the patients are shown in Table 1. The most frequent 
Table 1 The frequency of various symptoms and physical findings of the patients

\begin{tabular}{lc}
\hline \multicolumn{1}{c}{ Characteristic } & No. (\%) of patients (44) \\
\hline Age, years (mean \pm SD) & $25 \pm 18.6$ \\
Sex (male: female) & $1: 1.1(21: 23)$ \\
Symptoms & \\
Fever & $28(63.6)$ \\
Arthralgia & $24(54.5)$ \\
Myalgia & $19(43.2)$ \\
Fatigue & $8(18.9)$ \\
Back pain & $7(15.9)$ \\
Headache & $5(11.4)$ \\
Lack of appetite & $4(9.1)$ \\
Weight loss & $2(4.5)$ \\
Signs & \\
Hepatomegaly & $7(15.9)$ \\
Arthritis & $5(11.4)$ \\
Fever ( $\geq 38^{\circ} \mathrm{C}$ axillary) & $3(6.8)$ \\
Lymphadenopathy & $2(4.5)$ \\
Splenomegaly & $1(2.3)$ \\
Laboratory findings & \\
Leucocytosis $>10,000$ white blood cells per mm $\left.{ }^{3}\right)$ & $10(22.7)$ \\
Anaemia (hemoglobin $<12$ g/dL) & $1(2.3)$ \\
C-reactive protein positive & $7(15.9)$ \\
erythrocyte sedimentation rate $>20 \mathrm{~mm} / \mathrm{h}$ & $1(2.3)$ \\
alanine aminotransferase $>$ twice upper limit of normal & $1(2.3)$ \\
\hline
\end{tabular}

symptoms were fever (63.6\%) and arthralgia (54.5\%). The most frequent findings on physical examination were hepatomegaly (15.9\%) and arthritis (11.4\%). The most common laboratory findings were leukocytosis (22.7\%) and high CRP values (15.9\%). Fever (20.2\%), arthralgia (19.2\%), and weight loss (8.4\%) were more frequent in the person aged 0 to 14 years than in older individuals $(p<0.05)$. Also hepatomegaly $(17.9 \%)$ was more common in the 0 to 14 years age group $(p<0.05)$. There was no difference between age groups in terms of laboratory findings.

The STAT was positive in 42 of 44 (95.5\%) cases of brucellosis, with titers ranging from $1 / 160$ to $1 /$ 640. The STAT was negative in 2 cases of brucellosis (4.5\%), which were diagnosed on the basis of RPBT and a good response to antibrucellosis therapy (clinical and laboratory findings, especially leukocytosis and CRP, improved).

With regard to history and clinical findings, 3 (6.8\%) cases were evaluated as acute, 12 (27.3\%) as subacute, and $29(65.9 \%)$ as chronic. None of the cases of brucellosis had previously been treated.

Of the persons with brucellosis, 15 (34.1\%) had a history of raising livestock, 40 (90.9\%) reported having ingested unpasteurized milk or dairy products or both. There was family history of brucellosis in $81.8 \%$ of the cases.

Table 2 shows the association of seropositivity with different variables. Seropositivity was not significantly associated with sex or age group but was significantly associated $(p<0.05)$ with a family history of brucellosis, raising cattle, and consumption of unpasteurized milk and dairy products $(p<0.05)$.

When inhabitants were asked about the forms of contagion of brucellosis, $30.8 \%$ had never heard of brucellosis, and $50.3 \%$ were not aware of its forms of transmission.

The prevalence of brucellosis on area farms was studied by local veterinary officials, who found that $7.6 \%$ of cattle were infected with Brucella spp. Local public health measures were taken, and the uninfected cattle were vaccinated.

Various treatment regimens were administered to the 44 patients with brucellosis (Table 3). The duration of treatment was 6 weeks. The overall relapse rate was $9.09 \%$. The relapse rate of patients 


\section{Aypak, et al}

Table 2 Association between different variables and seropositivity for Brucella spp.

\begin{tabular}{|c|c|c|c|c|}
\hline \multirow{2}{*}{ Variable } & \multicolumn{2}{|c|}{ Brucellosis } & \multirow[t]{2}{*}{$\mathrm{P}$ value } & \multirow{2}{*}{ OR $(95 \% \mathrm{CI})$} \\
\hline & $\frac{\text { Positive }}{\mathrm{N}(\%)}$ & $\frac{\text { Negative }}{\mathrm{N}(\%)}$ & & \\
\hline \multicolumn{5}{|l|}{ Sex } \\
\hline Male & $21(9.2)$ & $208(90.8)$ & 0.568 & 4.32 (0.94 to 11.46$)$ \\
\hline Female & $23(8.5)$ & 249 (91.5) & & \\
\hline Total & $44(8.8)$ & $457(91.2)$ & & \\
\hline \multicolumn{5}{|l|}{ Age Group } \\
\hline 0-14 years & $21(11.1)$ & $168(88.9)$ & 0.089 & 2.41 (0.97 to 7.86$)$ \\
\hline $15-44$ years & $14(6.5)$ & $201(93.5)$ & & \\
\hline$>45$ years & $9(9.3)$ & $88(90.7)$ & & \\
\hline Total & $44(8.8)$ & $457(91.2)$ & & \\
\hline \multicolumn{5}{|c|}{ Family history of brucellosis } \\
\hline Yes & $36(11.4)$ & $281(88.6)$ & 0.038 & $2.19(0.89$ to 5.78$)$ \\
\hline No & $8(4.6)$ & $176(95.4)$ & & \\
\hline Total & $44(8.8)$ & $457(91.2)$ & & \\
\hline \multicolumn{5}{|c|}{ Consumption of raw milk and dairy products } \\
\hline Yes & $32(20.6)$ & $123(79.4)$ & 0.012 & 3.56 (1.14 to 7.13$)$ \\
\hline No & $12(3.5)$ & 334 (96.5) & & \\
\hline Total & $44(8.8)$ & 457 (91.2) & & \\
\hline \multicolumn{5}{|c|}{ Raising livestock } \\
\hline Yes & 34 (15.3) & $188(84.7)$ & 0.016 & 3.98 (1.09 to 8.09$)$ \\
\hline No & $10(3.6)$ & $269(96.4)$ & & \\
\hline Total & $44(8.8)$ & $457(91.2)$ & & \\
\hline
\end{tabular}

Table 3 Comparison of treatment outcome among different regimens

\begin{tabular}{lcc}
\hline \multicolumn{1}{c}{ Treatment regimen } & Number of cases & Relapses (\%) \\
\hline Doxycycline + rifampin & 24 & $3(12.5)$ \\
Doxycycline + rifampin + streptomycin* & 16 & $1(6.25)$ \\
Rifampin + co-trimoxazole & 4 & $0(0 \%)$ \\
\hline
\end{tabular}

*In this regimen streptomycin $1 \mathrm{~g}$ /daily was ordered for 14 days.

who received doxycyline and rifampin (12.5\%) was higher than that of patients treated with other regimens $(6.25 \%, p<0.05)$.

\section{Discussion}

Several clinical studies have indicated that brucellosis is a common health problem in rural and urban areas of Turkey ${ }^{4-9}$. The number of reported cases varies in different geographic regions of the country, and has been reported to be as high as $27.2 \%$ among high-risk patients in Eastern Anatolia $^{10,11}$. However, the seroprevalence rates obtained in previous studies do not correlate well with the prevalence of brucellosis based on the reported number of cases. This discrepancy might be explained by the differences in epidemiological conditions, because diagnoses in many cases of brucellosis are based on signs and symptoms and might, therefore, be inaccurate and lead to brucellosis being underreported in Turkey ${ }^{12}$. Also none of the surveillance studies in Turkey have reported cases of brucellosis that were active during the study period. To our knowledge, the present study is the first to investigate the seroprevalence for human brucellosis in Turkey during an outbreak among livestock; 3 (6.8\%) cases of brucellosis were acute, and $12(27.3 \%)$ cases were subacute. We found that brucellosis is strongly associated with a family history of brucellosis, consumption of unpasteurized 
dairy products, and raising cattle. Our findings are consistent with results of other studies ${ }^{4-9}$.

The primary transmission route of brucellosis in countries where it is endemic is the ingestion of unpasteurized milk or mild derivatives or both ${ }^{1}$. Most of the villagers in Aydinocak have retained their traditional habits and farming practices. The social habit of eating traditionally prepared soft cheeses was found to be an important epidemiological factor in contracting brucellosis in the Eastern Anatolia region ${ }^{11,13}$. In epidemiologic studies of brucellosis in Turkey, a history of raw dairy product consumption has been reported in $60 \%$ to $90 \%$ of cases $^{5,914}$. Dairy products are a principal means of transmitting brucellosis from animals to humans ${ }^{1}$. In our study, $34.1 \%$ of persons raised livestock, which is consistent with previous reports $^{4,5-9,14,15}$. Animals in Turkish villages are kept closely together in small stables. Therefore, infections can spread easily among animals and are easily transmitted to humans. None of the animals in our study had been vaccinated against brucellosis before the outbreak. In our study the seroprevalence rate was $8.8 \%$ and might be attributed to the high prevalence of Brucella spp. in animals (4.4\%), because the incidence of human brucellosis is positively correlated with the prevalence of brucellosis in animals $^{16,17}$. Mass vaccination of livestock is essential to control brucellosis and to reduce the incidence of human brucellosis. ${ }^{8}$ We found that a family history was a risk factor for brucellosis and indicates a common source of infection such as a habit of consuming unpasteurized dairy products. This finding is consistent with the result of another study from the Eastern Anatolia region and can be attributed to the eating of raw cheese by large families in this area ${ }^{4}$.

In the present study, $28 \%$ of patients with brucellosis complained of fever, but only $3 \%$ of patients were found to have elevated body temperatures. This finding is consistent with previous studies, which found that fever was a commonly reported symptom but was a less common sign ${ }^{4,17}$. Leukocytosis and increased CRP were the most prominent laboratory abnormalities seen in the acute and subacute cases of brucellosis ${ }^{4}$.
Serologic examination is the method of choice for diagnosing brucellosis when bacterial isolation is not possible ${ }^{1}$. The RBPT was positive in all patients and the STAT was positive in $95.5 \%$ of our study population; this finding is consistent with previous reports $^{4,13}$.

Our study has also found that villagers know little about brucellosis and suggests that prompt educational campaigns about brucellosis and other zoonoses are necessary.

The patients in the present study received various treatment regimens. Despite adequate treatment, acute brucellosis relapses in $5 \%$ to $40 \%$ of patients ${ }^{4,18}$. Also there is no standard therapy for chronic brucellosis ${ }^{19}$. The overall relapse rate in our study was $9.09 \%$. The highest relapse rate of $12.5 \%$ was for patients who received doxycycline and rifampin. In our study, the triple-agent treatment (doxycycline, rifampin, and streptomycin) regimen and the rifampin plus co-trimoxazole regimen were more effective than the doxycycline plus rifampin regimen. Large multicenter studies would be needed to determine the most appropriate treatment choices and durations in complicated brucellosis.

In conclusion, seroprevalence rates show that exposure to brucellosis remains common in rural communities in Turkey. Brucellosis can be eradicated in humans only by controlling the disease in animals. Public health and veterinary officials must make efforts to improve education regarding risk factors for brucellosis transmission, especially in rural areas, where human contact with domestic animals is widespread. Vaccination of all livestock is essential.

Conflicts of interest: None declared.

\section{References}

1. Young EJ: Brucella species. In Textbook of principles and practice of infectious diseases (Mandell GL, Bennett JE, Dolin R, eds), 5th ed. 2005; pp 2669-2674, Elsevier Churchill Livingstone, Philadelphia.

2. Pappas G, Papadimitriou P, Akritidis N, Christou L, Tsianos EV: The new global map of human brucellosis. Lancet Infect Dis 2006; 6: 91-99.

3. Alton GG, Jones LM, Pietz DE: Laboratory 
techniques in brucellosis, 2nd ed. 1975; World Health Organization, Geneva.

4. Buzgan T, Karahocagil MK, Irmak H, et al.: Clinical manifestations and complications in 1028 cases of brucellosis: a retrospective evaluation and review of the literature. Int J Infect Dis 2010; 14: 469-478.

5. Gur A, Geyik MF, Dikici B, et al: Complications of brucellosis in different age groups: a study of 283 cases in southeastern Anatolia of Turkey. Yonsei Med J 2003; 44: 33-44

6. Bodur H, Erbay A, Akinci E, Colpan A, Cevik MA, Balaban N: Neurobrucellosis in an endemic area of brucellosis. Scand J Infect Dis 2003; 35: 94-97.

7. Akdeniz H, Irmak H, Anlar O, Demiroz AP: Central nervous system brucellosis: presentation, diagnosis and treatment. J Infect 1998; 36: 297-301.

8. Tasbakan MI, Yamazhan T, Gokengin D, et al.: Brucellosis: a retrospective evaluation. Trop Doct 2003; 33: 151-153.

9. Tasova Y, Saltoglu N, Yilmaz G, Inal S, Aksu HSZ: Brucellosis: an evaluation of clinical, laboratory and treatment features. Turk J Infect 1998; 9: 263-265.

10. Cetin ET, Coral B, Bilgic A, Bilgehan E, Sipahioglu U, Gurel M: Türkiye'de insanda bruselloz insidansının saptanması. Doga-Turk J Med Sci 1990; 14: 324-334.

11. Ceylan E, Irmak H, Buzgan T, et al.: Van iline bağlı bazı köylerde insan ve hayvan populasyonunda bruselloz seroprevalansı. Van Tip Derg 2003; 10: 1-5.

12. Karabay O, Serin E, Tamer A, et al.: Hepatitis B carriage and Brucella seroprevalence in urban and rural areas of Bolu province of Turkey: a prospective epidemiologic study. Turk J Gastroenterol 2004; 15: 11-13.

13. Akdeniz H, Irmak H, Demiroz AP: Evaluation of brucellosis cases in Van region of Eastern Anatolia: a-3 year experience. Nagoya Med J 1998; 42: 101-110.

14. Demiroglu YZ, Turunç T, Calıkan H, Colakoglu S: Arslan H. Brucellosis: retrospective evaluation of the clinical, laboratory and epidemiological features in 151 cases. Mikrobiyol Bul 2007; 41: 517-527.

15. Savas L, Onlen Y, Savas N, Yapar AF, Aydin M, Onder T: Prospective evaluation of 140 patients with brucellosis in the southern region of Turkey. Infect Dis Clin Pract 2007; 15: 83-88.

16. Minas A, Minas M, Stournara A, Tselepidis S: The effects of Rev-1 vaccination of sheep and goats on human brucellosis in Greece. Prev Vet Med 2004; 64: 41-47.

17. Nicolletti P: The eradication of brucellosis in animals. Saudi Med J 1993; 14: 288-292.

18. Solera J, Martinez-Alfaro E, Espinosa A, Castillejos ML, Geijo P, Rodriguez Zapata M: Multivariate model for predicting relapse in human brucellosis. J Infect 1998; 36: 85-92.

19. Irmak H, Buzgan T, Karahocagil MK, Evirgen O, Akdeniz H, Demir AP: The effect of levamisole combined with the classical treatment for chronic brucellosis. Tohoku J Exp Med 2003; 20: 221-228.

(Received, September 9, 2011) (Accepted, March 21, 2012) 